Int. J. Electrochem. Sci., 12 (2017) $8982-8990$

\title{
Electrochemical Detection of As(III) Ions in Hot Spring Water Based on a $\mathrm{SiO}_{2}$-Au Nanocomposite
}

\author{
Feng Sun ${ }^{1}$ and Guojing Fan ${ }^{2, *}$ \\ ${ }^{1}$ School of Tourism and Land Resource, Chongqing Technology and Business University, Chongqing \\ 400067, China. \\ ${ }^{2}$ School of History Culture \& Tourism, GanNan Normal University, Ganzhou 341000, Jiangxi, China \\ *E-mail: fanguojing890@163.com
}

doi: $10.20964 / 2017.10 .76$

Received: 3 June 2017 / Accepted: 15 August 2017 / Published: 12 September 2017

I In this report, a $\mathrm{SiO}_{2}-\mathrm{Au}$ nanohybrid was prepared for the detection of $\mathrm{As}(\mathrm{III})$ ions using an electrochemical strategy. The morphology and properties of the $\mathrm{SiO}_{2}-\mathrm{Au}$ nanohybrid were characterized and analyzed via multiple techniques. Under optimized conditions, this nanohybrid material was utilized in the detection of As(III) in hot spring water samples collected from a tourist destination. The results suggested that an electrochemical sensor for the detection of As(III) could be used as a tool for the environmental protection of this tourist destination.

Keywords: As(III) ions; mesoporous silica; Gold; Electrochemical determination; Environmental protection

\section{FULL TEXT}

(C) 2017 The Authors. Published by ESG (www.electrochemsci.org). This article is an open access article distributed under the terms and conditions of the Creative Commons Attribution license (http://creativecommons.org/licenses/by/4.0/). 